\title{
Correction to: Social-psychological Determinants of the Implementation of Green Infrastructure for Residential Stormwater Management
}

Michael Drescher $\mathbb{1}^{1} \cdot$ Sarah Sinasac ${ }^{2}$

Published online: 20 February 2021

(c) Springer Science+Business Media, LLC, part of Springer Nature 2021

Correction to: Environmental Management

https://doi.org/10.1007/s00267-020-01393-3
In the original publication, the author name has been displayed incorrectly as "Michael Descher". The correct name of the author is "Michael Drescher".

The original article has been corrected.

The original article can be found online at https://doi.org/10.1007/ s00267-020-01393-3.

Michael Drescher

mdresche@uwaterloo.ca

1 School of Planning, University of Waterloo, 200 University Avenue West, Waterloo, ON N2L 3G1, Canada

2 Cooperation of the Town of Amherstburg, 271 Sandwich Street South, Amherstburg, ON N9V 2A5, Canada 